\title{
Digital vascular responses and serum endothelin-1 concentrations in primary and secondary Raynaud's phenomenon
}

The Queen's University of Belfast, Musculoskeletal Education and Research Unit, Musgrave Park Hospital, Stockmans Lane, Belfast BT9 7JB A E Smyth A L Bell

I N Bruce

Department of Physiology, The Queen's University of Belfast, Medical Biology Centre, 97 Lisburn Road, Belfast BT9 7BL

S McGrann

$\mathrm{J}$ A Allen

Correspondence to: Dr Smyth

anita.smyth@ntlworld.com

Accepted for publication 10 April 2000

\author{
A E Smyth, A L Bell, I N Bruce, S McGrann, J A Allen
}

\begin{abstract}
Objective-To determine circulating endothelin-1 levels (ET-1) in patients with primary or secondary associated Raynaud's phenomenon (RP) under resting conditions and in response to cold provocation.

Methods-Patients were categorised as primary RP (18) or scleroderma associated RP (14). Finger blood flow was measured by venous occlusion plethysmography at finger temperatures of $32^{\circ} \mathrm{C}$ and $24^{\circ} \mathrm{C}$. Vasospasm was detected as a finger systolic pressure of $0 \mathrm{~mm} \mathrm{Hg}$ after standardised provocative cooling. Severity of vasospasm was assessed by the level of cooling required to provoke spasm. Plasma ET-1 levels were measured in antecubital blood withdrawn under baseline conditions (finger $32^{\circ} \mathrm{C}$ ) and at the point of vasospasm. Measurements were also made in 19 matched control subjects.

Results-Finger blood flow was lower in patients with RP than in controls, with no difference between the two RP groups. Vasospasm occurred in all patients with RP but not in any control subjects and a grading system of severity was established. Baseline plasma ET-1 levels were similar in patients with RP and controls. Increases in ET-1 levels at the point of vasospasm in patients or corresponding timepoint in controls were also similar. There was no significant difference between the ET-1 levels in the two RP subgroups when the fingers were warm or when vasospasm was present.

Conclusions-These results do not support the hypothesis that ET-1 plays a part in the pathogenesis of RP. Objective testing is a useful adjunct to the clinical diagnosis of RP and allows assignment of a severity grade.

(Ann Rheum Dis 2000;59:870-874)
\end{abstract}

The condition characterised by "cold and white fingers" was classified as a disease entity by Raynaud in $1862^{1}$ yet the underlying cause is still uncertain. Evidence is accumulating that the episodic attacks are the consequence of a local fault in the digital vasculature rather than the result of sympathetic overactivity, as originally suggested by Raynaud himself. As knowledge has accumulated about the function of the endothelium derived vasoconstrictor molecule endothelin-1 (ET-1), it has been suggested that it may play a part in the pathogenesis of Raynaud's phenomenon (RP). ET-1 is known to be produced in endothelial and vascular smooth muscle cells, ${ }^{2}$ and stimuli such as hypoxia and catecholamines have been shown to induce transcription of ET- 1 mRNA. ${ }^{3}$ ET-1-induced vasoconstriction of dermal blood vessels has been demonstrated ${ }^{4}$ and raised plasma ET-1 levels have been found in response to a cold pressor test in normal subjects. ${ }^{5}$ This suggests an association between a rise in ET-1 levels and cold-induced vasoconstriction.

Several previous studies have investigated a possible role of ET-1 in Raynaud's phenomenon, ${ }^{6}$ but the numbers of patients studied were small and a clear distinction between primary and secondary forms was not always made. Furthermore, the diagnosis of RP was often a clinical one, made on history rather than on objective evidence of cold provoked vasospasm.

Our study aimed at determining whether circulating levels of ET-1 were increased in patients with either primary RP or scleroderma associated RP under resting conditions and after a standard cold challenge. The initial diagnosis of RP was based on the clinician's assessment and the use of Maricq's charts. The study incorporated objective testing for vasospasm to confirm the initial diagnosis and to establish a grading system for severity of the vasospastic condition.

\section{Subjects and methods}

PATIENTS

Thirty two patients with RP were identified after initial screening by clinical assessment and the use of Maricq's colour charts. ${ }^{7}$ The primary or secondary nature of the disease process was investigated by a thorough history and examination, assessment of nailfold capillary morphology, full blood picture, and erythrocyte sedimentation rate (Westergren technique). Antinuclear antibody, dsDNA, and extractable nuclear antigens, including anticentromere and Scl-70, were measured. All patients had radiographs of chest and hands.

Eighteen patients fulfilled LeRoy's criteria for primary RP. ${ }^{8}$ Fourteen had RP as part of a scleroderma spectrum disorder, ${ }^{9}$ of whom 11 had limited scleroderma, one had diffuse cutaneous scleroderma, and a further two had mixed connective tissue disease. ${ }^{10}$

Nineteen healthy control subjects were recruited and underwent screening clinical assessment, which included Maricq's colour charts. All controls had a normal erythrocyte sedimentation rate and a negative antinuclear antibody. These control subjects were individu- 
Table 1 Demographic features of patients with Raynaud's phenomenon (RP) and control subjects

\begin{tabular}{|c|c|c|c|}
\hline Feature & Primary $(n=18)$ & Secondary $(n=14)$ & Controls $(n=19)$ \\
\hline \multicolumn{4}{|l|}{ Age } \\
\hline Mean years (SD) & $38.5(12.6)$ & $40.4(11.6)$ & $38.1(11.9)$ \\
\hline Range & $21-58$ & $25-57$ & $23-61$ \\
\hline \multicolumn{4}{|l|}{ Sex } \\
\hline Male & 6 & 2 & 6 \\
\hline Female & 12 & 12 & 13 \\
\hline \multicolumn{4}{|l|}{ Smoking } \\
\hline Current & 1 & 1 & 1 \\
\hline Ex-smoker & 3 & 2 & 0 \\
\hline Never & 14 & 11 & 18 \\
\hline \multicolumn{4}{|l|}{ Disease duration } \\
\hline Mean years (SD) & $18.3(15.9)$ & $13.1(12.5)$ & 0 \\
\hline Range & $2-50$ & $2-42$ & \\
\hline \multicolumn{4}{|l|}{ Digital ulceration } \\
\hline Past history & 0 & 4 & 0 \\
\hline \multicolumn{4}{|l|}{ Surgical treatment } \\
\hline Sympathectomy & 0 & 0 & 0 \\
\hline \multicolumn{4}{|c|}{ Oral vasodilator treatment } \\
\hline Current & 2 & 6 & 0 \\
\hline Past & 14 & 2 & 0 \\
\hline Never & 2 & 6 & 0 \\
\hline \multicolumn{4}{|l|}{ Seasonal } \\
\hline Winter only & 4 & 0 & 0 \\
\hline All year & 14 & 14 & 0 \\
\hline \multicolumn{4}{|l|}{ Maricq category } \\
\hline White RP & 7 & 14 & 0 \\
\hline Blue RP & 1 & 0 & 0 \\
\hline \multicolumn{4}{|l|}{ Numbness } \\
\hline Present & 17 & 14 & 0 \\
\hline
\end{tabular}

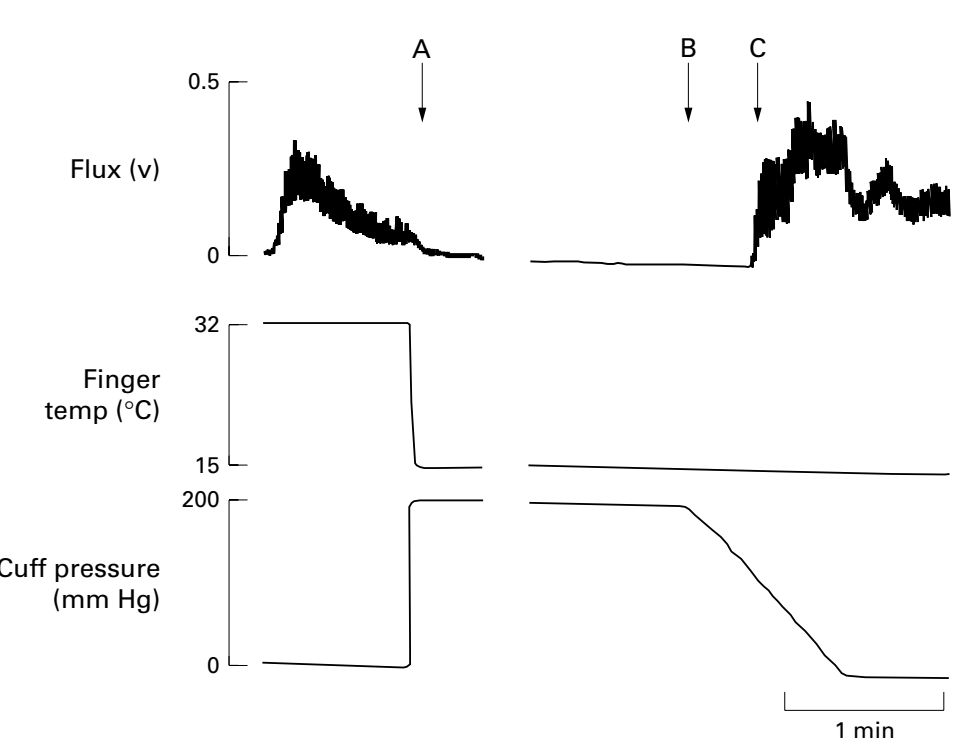

Figure 1 Measurement of finger systolic pressure after digital cooling in a control subject. The upper trace shows flux in fingertip skin. The middle trace shows temperature around the middle phalanx of the finger. The bottom trace shows pressure in the cuff surrounding the proximal phalanx. $A=$ proximal cuff inflation to $200 \mathrm{~mm} \mathrm{Hg}$ with simultaneous middle phalangeal cooling to $15^{\circ} \mathrm{C}$ abolishes flux; $B=$ after five minutes' cooling, gradual cuff deflation; $C=$ return of flux at cuff pressure of $120 \mathrm{~mm} \mathrm{Hg}$. Part of the recording during cooling and occlusion between $A$ and $B$ has been omitted.

ally matched to patients in each Raynaud's subgroup for sex, smoking status, and within an age range of -6 to +3 years. Table 1 gives details of patients and control subjects.

All patients and subjects gave written informed consent and approval for the study had been granted by the local research ethics committee.

EXPERIMENTAL PROTOCOL

All patients and control subjects abstained from caffeinated drinks, alcoholic beverages, undue physical exertion, and tobacco smoking on the morning or afternoon of their appointment. Any vasodilator drugs were stopped seven days before the study.
Subjects wearing only a light cotton suit lay supine (head elevation approximately $30^{\circ}$ ) in a temperature controlled chamber maintained initially at $24^{\circ} \mathrm{C}$. Brachial blood pressure was measured after a 10 minute equilibration period by auscultation, and then a heparinised $(10 \mathrm{U} / \mathrm{ml}) 21$ gauge $0.6 \mathrm{~mm}$ butterfly catheter was inserted into the antecubital fossa vein of the non-dominant arm. At the end of a 20 minute equilibration period a $5 \mathrm{ml}$ uncuffed blood sample was taken for measurement of ET-1. Room temperature was then adjusted to $20^{\circ} \mathrm{C}$.

Digital blood flow measurements

Finger blood flow was measured in one finger of each hand by venous occlusion plethysmography using fluid filled glass plethysmographs. ${ }^{11}$ The middle and distal phalanges of the most severely affected digit on each hand were inserted into the plethysmograph. If several digits were equally affected the middle finger was used.

After a 20 minute equilibration period, a series of 20 flows were recorded over a five minute period at a local digital temperature of $32^{\circ} \mathrm{C}$. The temperature of the fluid in the plethysmograph was then lowered to $24^{\circ} \mathrm{C}$ and seven minutes later a further 20 flows were recorded. The local temperature was returned to $32^{\circ} \mathrm{C}$ for a 10 minute "rewarming" period to allow the return of baseline blood flow.

Provocative cooling test

More severe localised cooling was then applied to the finger in an attempt to induce vasospasm. Blood cell flux in fingertip skin was recorded from a laser Doppler probe (Moore Instruments Ltd, Millwey, Axminster, Devon EX13 5DT). The middle phalanx was enclosed within a double lumen cuff, by means of which the basal local temperature of $32^{\circ} \mathrm{C}$ around the middle phalanx could be decreased to $15^{\circ} \mathrm{C}$ or $10^{\circ} \mathrm{C}$ within a few seconds. ${ }^{12}$ Finger cooling could be further increased by simultaneous inflation of a sphygmomanometer cuff $(30 \mathrm{~mm}$ wide) around the proximal phalanx to $200 \mathrm{~mm}$ $\mathrm{Hg}$ to prevent the inflow of warm arterial blood.

Measurement of baseline finger systolic pressure (FSP) at a local digital temperature of $32^{\circ} \mathrm{C}$ was performed in duplicate to give a resting control value. The proximal phalangeal cuff was inflated to $200 \mathrm{~mm} \mathrm{Hg}$ to abolish flux and then gradually deflated. The cuff pressure at which flux reappeared was taken as the resting FSP.

The middle phalanx was cooled to $15^{\circ} \mathrm{C}$ for five minutes with simultaneous digital artery occlusion. The cuff was then gradually deflated and FSP after cooling was recorded (fig 1). Absence of flux after cooling was recorded as zero FSP and was considered to indicate complete vasospasm (fig 2 ).

At the point of vasospasm an uncuffed blood sample was withdrawn from the antecubital venous catheter for subsequent ET-1 estimation. A similar sample was taken from the matched control subject's arm at the corresponding experimental time and temperature 


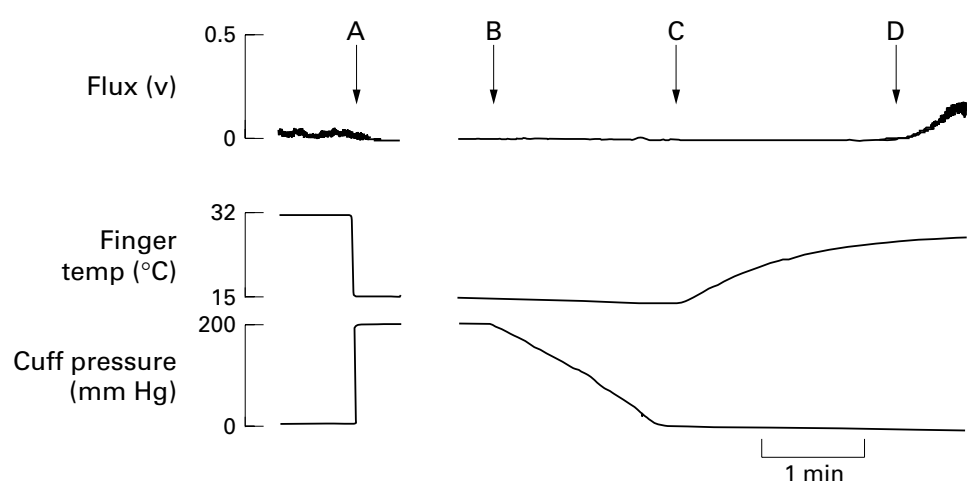

Figure 2 Measurement of finger systolic pressure after digital cooling in a patient with Raynaud's phenomenon. The upper trace shows flux in fingertip skin. The middle trace shows temperature around the middle phalanx of the finger. The bottom trace shows pressure in the cuff surrounding the proximal phalanx. $A=$ proximal cuff inflation to $200 \mathrm{~mm} \mathrm{Hg}$ with simultaneous middle phalangeal cooling to $15^{\circ} \mathrm{C}$ abolishes flux; $B=$ after five minutes' cooling, gradual cuff deflation; $C=$ no return of flux when cuff pressure is $0 \mathrm{~mm} \mathrm{Hg}$, rewarming started; $D=$ return of flux after digital rewarming. Part of the recording during cooling and occlusion between $A$ and $B$ has been omitted.

point. The local digital temperature was then returned to $32^{\circ} \mathrm{C}$ for a minimum of 10 minutes or until baseline digital flux had returned.

If no spasm was precipitated in a patient after cooling to $15^{\circ} \mathrm{C}$, the finger was rewarmed to $32^{\circ} \mathrm{C}$ and a more severe cooling stress $\left(10^{\circ} \mathrm{C}\right)$ was applied. Table 2 shows the sequence of cooling stresses used, the degree of cooling required to abolish flux indicating the severity of the vasospastic condition. Once a digit had exhibited vasospasm, no further cooling stimulus was applied to it.

\section{ENDOTHELIN-1 MEASUREMENTS}

Venous blood was placed in a pre-chilled plastic tube containing EDTA. The collection tube was immediately placed on ice. Samples were centrifuged for 10 minutes at $2500 \mathrm{rpm}$ at $4^{\circ} \mathrm{C}$; plasma was then separated and stored at $-70^{\circ} \mathrm{C}$ until assayed. Plasma ET-1 was determined by a commercially available assay (Parameter R\&D Systems Europe, Abingdon, UK). Extracted ET-1 was measured after

Table 2 The severity grading system used for the patients with Raynaud's phenomenon. All digital cooling stimuli were applied for five minutes to the middle phalanx. Additional hand cooling was achieved by the application of pre-chilled saline packs to both surfaces of the hand

\begin{tabular}{llll}
\hline $\begin{array}{l}\text { Environmental } \\
\text { temperature }\left({ }^{\circ} \mathrm{C}\right)\end{array}$ & Cooling stimulus to provoke spasm & Severity & $\begin{array}{l}\text { Grade of } \\
\text { patients }\end{array}$ \\
\hline 20 & Digit $15^{\circ} \mathrm{C}$, no occlusion & Very severe & 5 \\
20 & Digit $15^{\circ} \mathrm{C}$ with occlusion & Severe & 4 \\
20 & Digit $10^{\circ} \mathrm{C}$ with occlusion & Moderate & 3 \\
20 & Digit $10^{\circ} \mathrm{C}$ with occlusion and hand & Mild & 2 \\
& cooling to $12^{\circ} \mathrm{C}$ by pre-cooled packs & & 1 \\
& Room to $15^{\circ} \mathrm{C}$ for 10 min, then digit & Very mild & 1 \\
& $10^{\circ} \mathrm{C}$ with occlusion & No vasospasm & 0 \\
\hline
\end{tabular}

Table 3 Digital blood flow $\mathrm{ml} / 100 \mathrm{ml} / \mathrm{min}$ (mean (SD)) at local finger temperatures of $32^{\circ} \mathrm{C}$ and $24^{\circ} \mathrm{C}$ in 18 patients with primary Raynaud's phenomenon, 14 patients with secondary Raynaud's phenomenon, and their matched control subjects

\begin{tabular}{|c|c|c|c|c|}
\hline & $\begin{array}{l}\text { Primary } \\
(n=18)\end{array}$ & $\begin{array}{l}\text { Controls } \\
(n=18)\end{array}$ & $\begin{array}{l}\text { Secondary } \\
(n=14)\end{array}$ & $\begin{array}{l}\text { Controls } \\
(n=14)\end{array}$ \\
\hline \multicolumn{5}{|c|}{ Finger temperature $32^{\circ} \mathrm{C}$} \\
\hline Mean (SD) & $4.5(2.4)^{\star \star}$ & $8.9(3.9)$ & $4.1(2.3)^{\star \star \star}$ & $8.4(3.4)$ \\
\hline Range & $1.5-10.5$ & $3.5-16.5$ & $2.2-10.6$ & $3.8-16.5$ \\
\hline \multicolumn{5}{|c|}{ Finger temperature $24^{\circ} \mathrm{C}$} \\
\hline Mean (SD) & $1.7(1.1)^{\star}$ & $3.7(3.3)$ & $1.9(1.2)$ & $3.7(3.6)$ \\
\hline Range & $0.6-4.7$ & $1.0-15.4$ & $0.3-5.0$ & $1.6-15.4$ \\
\hline
\end{tabular}

Compared with controls: ${ }^{\star} \mathrm{p}=0.024 ;{ }^{\star \star} \mathrm{p}=0.001 ;{ }^{\star \star \star} \mathrm{p}<0.0001$. reconstitution in an enzyme linked immunosorbent assay (ELISA). The limit of detection, defined as the lowest concentration of ET-1 distinguishable from zero at the $95 \%$ confidence level, was $0.13 \mathrm{pg} / \mathrm{ml}$. Cross reactivity in this assay of big-ET, ET-2, and ET-3 was $<1 \%$, $<45 \%$, and $<14 \%$, respectively.

\section{STATISTICS}

Results were normally distributed and so comparisons between patients and matched controls were performed using paired $t$ tests. Comparisons between subgroups of cases were performed using the independent sample $t$ tests. The level of significance was taken as $\mathrm{p}<0.05$.

Measurements of finger blood flow and FSP were performed on both right and left sides. The bivariate coefficient was found to be $>0.8$ and, accordingly, further analyses were carried out on values which represented the mean for the right and left sides.

\section{Results}

DIGITAL BLOOD FLOW MEASUREMENTS

Finger blood flow for each patient or subject was calculated as the mean value of the 20 flows recorded at a particular local finger temperature.

When the fingers were warm at $32^{\circ} \mathrm{C}$, finger blood flow was significantly lower in the patients with both primary $(\mathrm{p}=0.001)$ and secondary $\mathrm{RP}(\mathrm{p}<0.0001)$ than in their matched control subjects (table 3 ). When the finger temperature was lowered to $24^{\circ} \mathrm{C}$, both Raynaud's groups exhibited lower finger flow than their controls, but the difference was significant $(p=0.024)$ only for the primary group. Finger blood flows at $32^{\circ} \mathrm{C}$ and $24^{\circ} \mathrm{C}$ were similar in the primary and secondary Raynaud's groups.

\section{DIGITAL AND BRACHIAL PRESSURE}

MEASUREMENTS

Baseline mean brachial systolic blood pressure measurements were similar in the patients with primary and secondary RP and their matched controls.

When the fingers were warm at $32^{\circ} \mathrm{C}$ mean FSP was lower in both the primary $(p=0.02)$ and secondary $(\mathrm{p}<0.0001)$ Raynaud's groups than in the matched control groups. Likewise the ratio of FSP:brachial systolic pressure was significantly lower in the primary $(p=0.001)$ and secondary $(\mathrm{p}<0.0001)$ Raynaud's groups than in their matched control groups (table 4). FSP measurements were similar in the two Raynaud's subgroups as were the FSP:brachial pressure ratios.

Vasospasm was provoked in all the patients with RP by one of the standard cooling protocols detailed in table 2. None of the control subjects exhibited vasospasm with even the most severe cooling stimulus. Table 5 summarises the outcome of the provocative cooling tests.

\section{ENDOTHELIN-1 (ET-1) MEASUREMENTS}

Table 6 shows values of ET- 1 measurements. When the fingers were warm at $32^{\circ} \mathrm{C}$ the ET- 1 levels were not significantly different in either 
Table 4 Mean brachial and finger systolic pressure measurements ( $\mathrm{mm} \mathrm{Hg}$ ), and ratio of finger:brachial in 18 patients with primary Raynaud's phenomenon, 14 patients with secondary Raynaud's phenomenon, and their matched control subjects. Local finger temperature was $32^{\circ} \mathrm{C}$. Values are mean (SD)

\begin{tabular}{lllll}
\hline & Primary & Controls & Secondary & Controls \\
\hline Brachial systolic & $119(10.7)$ & $112(12.2)$ & $111(11.5)$ & $116(12.1)$ \\
Range & $98-130$ & $95-135$ & $98-130$ & $100-130$ \\
Finger systolic & $93(18.8)^{\star}$ & $108(15.5)$ & $84(18.9)^{\star \star \star}$ & $112(13.8)$ \\
Range & $62-125$ & $82-141$ & $61-111$ & $88-132$ \\
Ratio & $0.78(0.16)^{\star \star}$ & $0.96(0.07)$ & $0.76(0.15)^{\star \star \star}$ & $0.97(0.06)$ \\
Range & $0.54-1.05$ & $0.87-1.1$ & $0.47-0.94$ & $0.84-1.1$ \\
\hline
\end{tabular}

Compared with controls: ${ }^{\star} \mathrm{p}=0.02 ;{ }^{\star \star} \mathrm{p}=0.001 ;{ }^{\star \star \star} \mathrm{p}<0.0001$.

Table 5 Severity of vasospasm in the patients with primary and secondary Raynaud's phenomenon and their matched control subjects as determined by the cold provocation tests

\begin{tabular}{llllll}
\hline $\begin{array}{l}\text { Primary } \\
(n=18)\end{array}$ & $\begin{array}{l}\text { Controls } \\
(n=18)\end{array}$ & $\begin{array}{l}\text { Secondary } \\
(n=14)\end{array}$ & $\begin{array}{l}\text { Controls } \\
(n=14)\end{array}$ & $\begin{array}{l}\text { Descriptive } \\
\text { grade }\end{array}$ & $\begin{array}{l}\text { Numerical } \\
\text { grade }\end{array}$ \\
\hline 2 & 0 & 2 & 0 & Very severe & 5 \\
4 & 0 & 5 & 0 & Severe & 4 \\
2 & 0 & 5 & 0 & Moderate & 3 \\
7 & 0 & 2 & 0 & Mild & 2 \\
3 & 0 & 0 & 0 & Very mild & 1 \\
0 & 18 & 0 & 14 & No spasm & 0 \\
\hline
\end{tabular}

Table 6 Plasma endothelin-1 (ET-1) levels in pg/ml (mean (SD)) at baseline and at the point of vasospasm in 18 patients with primary Raynaud's phenomenon, 14 patients with secondary Raynaud's phenomenon, and their matched control subjects. The range is also given and the percentage change in ET-1 at the point of vasospasm

\begin{tabular}{lllll}
\hline & Primary & Controls & Secondary & Controls \\
\hline Baseline ET-1 $(\mathrm{pg} / \mathrm{ml})$ & $0.59(0.25)$ & $0.54(0.21)$ & $0.66(0.3)$ & $0.57(0.23)$ \\
Range & $0.20-1.02$ & $0.13-1.05$ & $0.35-1.37$ & $0.13-1.05$ \\
Increase in ET-1 at vasosopasm $(\mathrm{pg} / \mathrm{ml})$ & $0.15(0.22)$ & $0.14(0.12)$ & $0.07(0.16)$ & $0.13(0.11)$ \\
Percentage change & $36.8(61.5)$ & $37.6(41.2)$ & $17.9(33.7)$ & $30.1(24.3)$ \\
\hline
\end{tabular}

the primary or secondary Raynaud's groups compared with their controls. ET-1 levels measured at the point of vasospasm in the patients and at a corresponding point in the control subject experiments were similar.

When the Raynaud's subgroups were compared, the ET-1 levels were not significantly different either at $32^{\circ} \mathrm{C}$ or at the point of vasospasm.

\section{Discussion}

This study is among the largest to date examining baseline and cold stimulated levels of ET-1 in patients with primary and secondary RP. No difference was found between baseline and cold stimulated ET-1 levels in the RP subcategories. Digital blood flow was found to be significantly lower in subjects with RP than in controls at $24^{\circ} \mathrm{C}$ and $32^{\circ} \mathrm{C}$, but the considerable overlap in the individual absolute values limits its usefulness as a diagnostic tool. Objective tests showed vasospasm and subsequently allowed further categorisation according to severity.

A clear strength of this study was the stringent methods used, firstly, in the diagnosis of RP and, secondly, in the subsequent subcategorisation of subjects into primary and secondary RP. The diagnosis of RP was based on the typical history given by the patient and the clinical judgment of the doctor. Recognition by the patient of the characteristic colour changes in Maricq colour charts was also used to confirm the diagnosis. Subsequent provocative cooling tests induced total vasospasm in all patients, thus objectively confirming the diagnosis of RP. Further standard investigations were employed to subdivide the patients with
RP into primary and secondary groups. All subjects designated as controls had no signs or symptoms of any relevant clinical conditions. They subsequently all tested negative for vasospasm in the provocative cooling tests.

Baseline ET-1 samples were obtained at an ambient temperature of $24^{\circ} \mathrm{C}$. This is thermoneutral, well below the thermal sweating threshold, but warm enough not to trigger vasospasm in the patients. The finding that ET-1 levels did not differ at baseline is contrary to earlier reports, which described higher baseline ET- 1 concentrations in seven patients with primary RP relative to controls ${ }^{13}$ and mildly raised baseline levels in 15 patients compared with controls. ${ }^{14}$ The present findings concur with the baseline studies of Smits et al, who studied a mixed group of 10 patients with primary and scleroderma associated RP. ${ }^{15}$

Neither the plasma ET-1 concentration measured at the point of vasospasm nor its change from baseline level differed significantly from corresponding values for the matched control groups. Again, this differs from the results reported by Zamora et al, who reported a threefold rise in ET-1 concentration in subjects with primary RP. ${ }^{13}$ Kanno et al found an increase in plasma ET-1 levels after cold challenge in four of five subjects with secondary $R P,{ }^{16}$ though there was no significant change as a whole. However, other investigators have found no definite relation between onset of vasospasm and changes in the ET-1 plasma levels from resting baseline values. ${ }^{6}{ }^{17}$

There are several possible explanations for the differing findings reported. These are due to the inherent problems in assessing the role of ET-1 in the regulation of vascular tone of the peripheral circulation. Firstly, ET-1 secretion is directed at the abluminal side of the endothelial cell, with more than $80 \%$ of the total amount secreted towards the underlying smooth muscle. Thus plasma ET-1 may represent only the overspill of ET-1 molecules unattached to specific receptors. Furthermore, measured plasma ET-1 levels not only reflect the balance between the production and binding to the receptor but also differences in degradation and renal clearance. Conceivably, this balance is variable in individual patients with scleroderma and primary RP because of different affinities of their endothelin receptors. Perhaps more importantly, the site of sampling in the antecubital fossa is not close enough to the site of digital vasospasm to reflect accurately any associated rapid fluctuations in ET-1 concentration.

The functional significance of the raised serum ET-1 reported by some in RP remains uncertain as the concentrations are several orders lower than those needed to induce constriction in isolated vascular rings. ${ }^{18}$ Thus circulating ET-1 may not be of direct importance but might be an indicator of more functionally significant local release. It may be that endothelial or abluminal release of ET-1 mediates vasoconstriction, and the incidental luminal release into the serum could be delayed. Therefore a more detailed study using frequent 
sampling might determine whether ET-1 plays a part in the pathogenesis of RP.

It is recognised that endothelial cell activation is a two stage process requiring time for the stimulating agent to cause an effect through gene transcription and protein synthesis. ${ }^{19}$ It may be that cold induces the initial vasospasm through an alternative mechanism (for example, sympathetic stimulation) and that the subsequent ET-1 production by endothelial cells after exposure to a stimulus such as catecholamines or hypoxia is responsible for the prolonged vasoconstriction seen. ${ }^{20}$

Objective testing under standardised conditions has been shown to be a useful adjunct in the definitive diagnosis of vasospastic disorders and can also provide a method for grading. ${ }^{21}{ }^{22}$ An objective system is invaluable in grading the severity of a disease process in which diagnosis and assessment depend largely on subjective reports by the patient. Such a system is of particular relevance in following the rate of disease progression over a period of time, in quantifying the response to treatment, and as part of the medicolegal assessment of vibration white finger. The concept underlying the grading system was that in a patient with severe RP, vasospasm should be induced by a relatively minor cold stress, whereas in patients with mild vasospastic disease a greater cold stress should be necessary to induce vasospasm.

When the digit was warm, baseline FSP and the ratio FSP:brachial pressure were significantly lower in both groups of patients with RP than in their matched control subjects. Although this concurs with the findings of Maricq et $a l,{ }^{21}$ the variation between subjects made it unsuitable as a diagnostic measure. Moreover, perhaps surprisingly, FSP was similar in the primary and scleroderma associated Raynaud's groups.

Laser Doppler flowmetry was used to indicate FSP (the reopening pressure) in the digit after local cooling. This provided a sensitive and specific indication of the presence or absence of cold induced vasospasm. ${ }^{12}$ However, it must be noted that zero reopening pressure after cooling is not always associated with the typical colour changes of a spontaneous Raynaud's episode. Therefore, the diagnosis was based on a zero reopening pressure, and documentation of colour changes was not part of the standard diagnosis in this study. The zero reading relates to the absence of red cell flux in the fingertip skin under the laser Doppler probe and may therefore result from closure of blood vessels in the cutaneous microcirculation or from digital artery closure.

The pathophysiology of RP is likely to be multifactorial and include factors which reduce basal blood flow and increase sensitivity to cold stimuli. The results of this study do not support the concept of a major role for ET-1 in the gen- esis of vasospasm in patients with RP. Local production of ET-1 may be of central importance, but measurement of circulating levels may not accurately reflect the potential or actual role of this molecule.

Further clarification of the role of ET-1 in $\mathrm{RP}$ will require careful studies on large numbers of patients in clearly defined disease subgroups employing more frequent ET-1 sampling and the use of specific endothelin blocking agents.

We are grateful to Ms Sophie Copeland for performing the ET-1 assays.

Dr Smyth was funded by a Royal Victoria Hospital Clinical Fellowship and a project grant from the UK Raynaud's and Scleroderma Group.

1 Raynaud M. De l'asphyxic locale et de la gangrene symetrique des extremities. London:The Sydenham Society, 1862:1199. (Selected monographs 121 London translation.)

2 Ohlstein E, Elliot J, Giora Z, Feuerstein GZ, Ruffulo R. Endothelin receptors: receptor classification, novel receptor antagonists, and potential therapeutic targets. Med Res Rev 1996;16:365-90.

3 Hocher B, Thone-Reinke C, Bauer C, Raschack M, Neumayer HH. The paracrine endothelin system: pathophysiology and implications in clinical medicine. Eur J Chem Clin Biochem 1997;35:175-89.

4 Brain S, Tippins J, Williams T. Endothelin induces potent microvascular constriction. $\mathrm{Br} J$ Pharmacol 1988;95: 1005-7.

5 Fyhrquist F, Saijonmaa O, Metsarinne K, Tikkanen I, Rosenlof K. Raised endothelin-1 concentration following cold pressor test. Biochem Biophy Res Commun 1990; 169:217-21

6 Yamane K, Miyauchi T, Suzuki N, Ferran C, Stuhlmeier, Wrighton CJ, et al. Significance of plasma endothelin-1 levels in patients with systemic sclerosis. J Rheumatol 1992;19:1566-71.

7 Maricq H, Weinrich M. Diagnosis of Raynaud's phenomenon assisted by color charts. J Rheumatol 1988;15:454-9.

8 LeRoy E, Medsger TA. Raynaud's phenomenon: a proposal for classification. Clin Exp Rheumatol 1992;10:485-8.

9 LeRoy EC, Black C, Fleischmajer R, Jablonska S, Krieg T, Medsger TA, et al. Scleroderma: classification, subsets and Medsger TA, et al. Scleroderma: classification,

10 Alarcon-Segovia D. Mixed connective tissue disease-a decade of growing pains. J Rheumatol 1981;8:535-40.

11 McGrann S, Irwin S, Allen J. A plethysmograph for the measurement of digital blood flow. J Med Eng Technol 1986;10:329-31.

12 Allen J, Devlin M, McGrann S, Doherty C. An objective test for the diagnosis of vasospasm in patients with Raynaud's syndrome. Clin Sci 1992;82:529-34.

13 Zamora M, O'Brien R, Rutherford R, Weil J. Serum endothelin-1 concentrations and cold provocation in primary Raynaud's phenomenon. Lancet 1990;336: 1144-7.

14 Cimminiello C, Milani M, Uberti T, Arapia G, Perolini S, Bonfardeci G. Endothelin, vasoconstriction and endothelial damage in Raynaud's phenomenon. Lancet 1991;337: 114-15.

15 Smits P, Hofmann H, Rosmalen F, Wollersheim H, Thien T. Endothelin-1 in patients with Raynaud's phenomenon. Lancet 1991;337:236.

16 Kanno K, Hirata Y, Emori T. Endothelin and Raynaud's phenomenon. Am J Med 1991;90:130-2.

17 Kahaleh M. Endothelin, an endothelium-dependent vasoconstrictor in scleroderma. Arthritis Rheum 1991;34:97883.

18 Yanagisawa $M$, Kurihara $H$, Kimura $S$, Tomobe $Y$, Kobayashi M, Mitsui Y. A novel potent vasoconstrictor peptide produced by vascular endothelial cells. Nature 1988;32:411-15.

19 Bach F, Robson S, Winkler H, Yuhara T, Akama I, Suzuki $\mathrm{H}$, et al. Barriers to xenotransplantation. Nature Med 1995;1:869-73.

20 Levin E. Endothelins: mechanism of disease. N Engl J Med 1995;333:356-63.

21 Maricq HR, Weinrich MC, Valter I, Palesch Y, Maricq J. Digital vascular responses to cooling in subjects with cold sensitivity, primary Raynaud's phenomenon, or sclerosensitivity, primary Raynaud's phenomenon, or sclero-
derma spectrum disorders. J Rheumatol 1996;23:2068-78.

22 Kallenberg CG, Wouda AA, The TH. Systemic involvement and immunologic findings in patients presenting with Raynaud's phenomenon. Am J Med 1980;69:675-80. 